\title{
Systemic RNA oxidation can be used as an index of clinical infection and prognosis in a Vibrio parahaemolyticus Challenge Rat Model
}

Yaya Pian ( $\nabla$ pianyaya0919@163.com )

Beijing Hospital https://orcid.org/0000-0002-1519-3947

Jing-Jing Nie

Beijing Hospital

Chen-Chen Wang

Beijing Hospital

Qian Liu

Beijing Hospital

Zhen Liu

Beijing Hospital

Wei Zhang

Beijing Hospital

Li-qun Zhang

Beijing Hospital

Qiu-geng Ou-Yang

Beijing Hospital

Guo-Qing Fan

Beijing Hospital

Lv-Tao Zeng

Beijing Hospital

Zhen-Xiang Gao

Beijing Hospital

Ji-Hong Hu

Beijing Hospital

Jian-Ping Cai

Beijing Hospital

\section{Research}

Keywords: 
Posted Date: April 7th, 2020

DOl: https://doi.org/10.21203/rs.3.rs-21144/v1

License: (c) (i) This work is licensed under a Creative Commons Attribution 4.0 International License. Read Full License 
1 Systemic RNA oxidation can be used as an index of clinical infection and

2 prognosis in a Vibrio parahaemolyticus Challenge Rat Model

4 Ya-Ya Pian "\#, Jing-Jing Nie 1\#, Chen-Chen Wang 2, 3, Qian Liu ${ }^{3}$, Zhen Liu 2, Wei Zhang ${ }^{4}$,

5 Li-Qun Zhang 2, Qiu-geng Ou-Yang ${ }^{3}$, Guo-Qing Fan ${ }^{2}$ Lv-Tao Zeng 2 , Zhen-Xiang Gao ${ }^{1}$,

6 Ji-Hong Hu ${ }^{1 *}$ and Jian-Ping Cai ${ }^{2 *}$

7

$8 \quad{ }^{1}$ National Center for Clinical Laboratories, Beijing Hospital, National Center of Gerontology;

9 Institute of Geriatric Medicine, Chinese Academy of Medical Sciences, Beijing 100730, China;

$10{ }^{2}$ The Key Laboratory of Geriatrics, Beijing Institute of Geriatrics, Beijing Hospital, National

11 Center of Gerontology, National Health Commission; Institute of Geriatric Medicine, Chinese

12 Academy of Medical Sciences, Beijing 100730, China; ${ }^{3}$ Department of Pharmacy, Wenzhou

13 Medical University, Wenzhou 325035, China; ${ }^{4}$ Department of Pathology, Beijing Hospital,

14 National Center of Gerontology, Beijing 100730, China

16 \#These authors contributed equally to this work.

18 *To whom all correspondence should be addressed. E-mail: caijp61@vip.sina.com 19 and hujh68@126.com. 


\section{ABSTRACT}

Background: More and more evidence supports the concept that RNA oxidation plays

a substantial role in the progress of multiple diseases; however, only a few studies have reported RNA oxidation caused by microbial pathogens. Urinary 8-oxo-7,8dihydroguanosine (8-oxo-Gsn) and 8-oxo-7,8-dihydro-2'-deoxyguanosine (8-oxodGsn), which are broadly used as indicators of oxidative damage of RNA and DNA, were analyzed in this study to determine which can be used as an index of clinical infection and prognosis in a Vibrio parahaemolyticus challenge rat model. In this study, twenty-four specific-pathogen-free (SPF) male SD rats were randomly divided into two groups: an infection group and a phosphate-buffered saline (PBS) control group. An LC-MS/MS-based system was established to determine the 8-oxo-dGsn and 8-oxoGsn contents of urine samples. The immunohistochemistry (IHC) was used to determine the 8-oxoguanine in nuclear DNA and in cellular RNA of different tissues of rats. Hematoxylin-eosin (H\&E) stain was used to analyze intestinal inflammation. ELISA were used to detect the level of inflammatory factors in serum. In addition, body temperatures, body weights, bacterial burden of Vibrio parahaemolyticus were also detected.

Results: The level of urinary and tissular 8-oxo-Gsn rather than 8-oxo-dGsn was significantly increased after infection with $V$. parahaemolyticus compared with PBS control. Stimultaneously, intestinal inflammation, the numbers of white blood cells (WBCs) and inflammatory factors (including CRP, IL-6, IL-1 $\beta$, TNF- $\alpha$, IL-10 and IL- 
43 17A) were increased sharply. What is clinical significance is that the trend of urinary

44 8-oxo-Gsn was consistent with WBCs or inflammation. It is more important that the

45 concentration of urinary 8-oxo-Gsn in the infection group was positively correlated with

$46 \quad$ WBCs and inflammatory cytokines.

47 Conclusion: Our results demonstrated that 8-oxo-Gsn can be used as a more effective biomarker of clinical infection and prognosis compared with classic clinical

49 indicators such as IL-6 and TNF- $\alpha$.

50 Keywords: RNA oxidation; 8-oxo-Gsn; inflammation; Vibrio parahaemolyticus 
More and more evidence supports that RNA oxidation plays a substantial role in the progress of multiple diseases, such as Alzheimer's disease ${ }^{1}$, diabetes ${ }^{2}$ and aging ${ }^{3}$, and plenty of studies have reported microbial pathogens can induce the increase of oxidative stress and inflammation ${ }^{4-7}$. However, only a few studies have reported RNA oxidation caused by microbial pathogens ${ }^{8}$.

Vibrio parahaemolyticus, a Gram-negative halophilic bacterium that inhabits marine, estuarine and coastal waters around the world ${ }^{9-11}$, is the main pathogen responsible for human acute gastroenteritis after consuming contaminated raw or undercooked seafood ${ }^{12,13}$. Many gastroenteritis cases of $V$. parahaemolyticus have been reported worldwide, including Asia and the USA ${ }^{9,14}$, and clinical symptoms of $V$. parahaemolyticus include diarrhea, abdominal cramps, vomiting, headaches and a fever ${ }^{15}$. Owing to the clinical significance of $V$. parahaemolyticus, it was used as an infection model to study RNA oxidation in our research.

Reactive oxygen species (ROS) are constantly produced intracellularly under physiological conditions as a result of cellular metabolism and external conditions ${ }^{16}$. Persistently generated ROS can damage macromolecules, such as nucleic acids, protein and lipids, subsequently resulting in various diseases. Such nucleic acid oxidation plays crucial roles in the pathophysiology progress of various diseases ${ }^{17} .8$ oxoguanine in nuclear DNA and in cellular RNA are the most widely used indicators of oxidative stress ${ }^{18,19}$, and many studies have shown 8 -oxoguanine is a perfect marker for the detection of oxidative stress $20-23$. 

oxidative damage of RNA and DNA, were analyzed in this study. An LC-MS/MS-based system was established to determine the 8-oxo-dGsn and 8-oxo-Gsn contents of urine samples. The immunohistochemistry (IHC) was used to determine the 8-oxoguanine in nuclear DNA and in cellular RNA of different tissues of rats. Hematoxylin-eosin (H\&E) stain was used to analyze intestinal inflammation. Sysmex XS-1000i hematology was used to analyze WBCs in blood. Luminex and ELISA methods were used to detect the level of inflammatory factors in serum. We herein provide evidence that urinary 8-oxoGsn can be used as a more effective biomarker of clinical infection and prognosis compared with classic clinical indicators such as CRP or IL-6.

97 


\section{Results}

\section{RNA Oxidation Increased in Urine after Infection with V. parahaemolyticus}

The level of 8-oxo-Gsn and 8-oxo-dGsn in urine samples was measured by the UHPLC-MS/MS method. Figure 1 showed the concentration of 8-oxo-Gsn and 8-oxodGsn in urine samples of SD rats (PBS control versus V. parahaemolyticus-infected). From Figure 1A, we can see that the level of urinary 8-oxo-Gsn in infection group was sharply increased from D1 to D5, peaking at D5 and gradually decreased thereafter, especially at $\mathrm{D} 13$, the level had almost returned to the pre-infection (D0). About the PBS control animals, the level of urinary 8-oxo-Gsn always kept a steady baseline. Creatinine (Cre) was used for normalizing the oxidized guanosine level. There was not statistically significant difference of 8-oxo-dGsn in urine at any time between these two groups, and the value was much lower than 8-oxo-Gsn (Figure 1B). In summary, our results showed that the level of urinary 8-oxo-Gsn other than 8-oxo-dGsn was dramatically increased after infection with $V$. parahaemolyticus.

\section{RNA Oxidation Increased in Tissues after Infection with $V$. parahaemolyticus}

Corresponding antibodies were used to detect 8-oxo-dGsn in nuclear DNA and 8oxo-Gsn in cellular RNA of SI, spleen, colon and liver of SD rats challenged with $V$. parahaemolyticus at D0, D1, D5. To detect 8-oxo-Gsn in cellular RNA, immunostaining using antibodies against 8-oxoGsn was performed. The level of 8-oxo-Gsn in cellular RNA in SI and spleen was boosted gradually from D0 to D5, which was different from colon and liver, they peaked at D1 (Figure 2A). To detect 8-oxo-dGsn in nuclear DNA, antibodies against 8-oxo-dGsn were applied to tissue sections. From Figure 2B, we 
can see that there was not statistically significant difference in SI, spleen or liver from beginning to end, but 8-oxo-dGsn in colon was boosted from D0 to D5 and peaked at D1. In a word, our results demonstrated that 8-oxo-Gsn in cellular RNA other than 8oxo-dGsn in nuclear DNA maybe a systemic biomarker after infection with $V$. parahaemolyticus.

\section{Inflammation Enhanced after SD Rats Challenged with V. parahaemolyticus}

Inflammation was detected in colon of SD rats after challenge with this bacteria.

$\mathrm{H} \& \mathrm{E}$ stain of the colon of the infected rats at D0, D1, D5, D9 and D18 was shown in Figure 3A. There was a bit lymphocytes infiltration under physiological conditions (D0), the red arrows showed the infiltration of lymphocytes in colon. However, lymphocytes infiltration increased quickly from D1 to D5, then gradually decreased from D5 to D18, especially dropping particularly low at D18 (back to almost physiological state).

We also counted the WBCs in blood, which was as low as PBS-treated control animals before infection but sharply increased from D1 to D5 and peaked at D5 before gradually decreased from D5 to D18. The WBCs remained at a very low level in PBS group animals. The body temperatures and body weights were also determined, yet there was no significant difference (supplementary Figures 1/2, respectively). The bacterial burden in stool gradually decreased, and no bacteria detected at D11, which was shown in supplementary Figure 3. No V. parahaemolyticus were observed in stool in PBS control animals, indicating that the animals were not contaminated. In summary, our results showed that inflammation was enhanced after SD rats were challenged with V. parahaemolyticus. 


\section{Upregulation of Inflammatory Cytokines in Serum Samples}

In addition to the infiltration of lymphocytes and WBCs, the inflammatory cytokines were also detected in our research. Several significant inflammatory cytokines were tested in the serum samples, including IL-6, IL-10, TNFa, IL-1 $\beta$, IL-17A and CRP. IL6, IL-10, TNF- $\alpha$, IL-1 $\beta$ and IL-17A were analyzed using the Luminex system, which were shown in Figures $4 \mathrm{~A}$ to $4 \mathrm{E}$. CRP was detected using the ELISA method, which was shown in Figure 4F. From Figure 4 we can see that inflammatory cytokines were dramatically increased from D1 to D5 after infection, peaking at D5 and gradually decreased from D5 to D18. As a PBS control, there was not statistically significant difference at any time in our study.

\section{Correlation analysis of 8-oxo-Gsn with WBCs and inflammatory cytokines}

The concentration of urinary 8-oxo-Gsn in the infection group was positively correlated with WBCs $(r=0.454, P<0.0001)$ and inflammatory cytokines: CRP $(r=0.678$, $P<0.001)$, IL-6 ( $r=0.279, P<0.05), I L-10(r=0.409, P<0.001)$, TNF- $\alpha(r=0.457, P<0.001)$, IL-1 $\beta(r=0.604, P<0.001)$ and IL-17A $(r=0.543, P<0.001)$. The predictive value of 8oxo-Gsn, WBCs and inflammatory cytokines was assessed by the ROC curve. From Figure 5, we can see that the area under ROC curve of urinary 8-oxo-Gsn, WBCs, CRP, IL-6, IL-10, TNF- $\alpha$, IL-1 $\beta$ and IL-17A was 0.778 (95\% Cl, 0.629-0.926, P<0.001), $0.883(95 \% \mathrm{Cl}, 0.798-0.967, \mathrm{P}<0.001), 0.972(95 \% \mathrm{Cl}, 0.935-1.009, \mathrm{P}<0.001), 0.739$ (95\% Cl, 0.605-0.874, $\mathrm{P}<0.001), 0.912(95 \% \mathrm{Cl}, 0.831-0.994, \mathrm{P}<0.001), 0.942$ (95\% $\mathrm{Cl}, 0.869-1.014, \mathrm{P}<0.001), 0.953(95 \% \mathrm{Cl}, 0.908-0.997, \mathrm{P}<0.001)$, and $0.919(95 \% \mathrm{Cl}$, $0.855-0.983, P<0.001)$, respectively. These statistic analysis confirmed that $8-0 x 0-G s n$ 
164 was closely related with inflammation.

165

166

167

168

169

170

171

172

173

174

175

176

177

178

179

180

181

182

183

184

185 


\section{Discussion}

The present study showed that RNA oxidation dramatically elevated in urine and tissues of rats after infection with $V$. parahaemolyticus. RNA oxidation, which plays a substantial role in the progress of multiple diseases, have studied in many fields, such as diabetes and aging, but only a few studies have reported in microbial pathogens. For this purpose, we studied RNA oxidation caused by microbial pathogens.

As by-products of oxidative stress, 8-oxo-Gsn other than 8-oxo-dGsn has shown increased in urine and partial tissues after challenge with $S$. Enteritidis ${ }^{8}$. However, it doesn't compare with other classic clinical indicators such as CRP or IL-6, and also doesn't prove whether other pathogens can cause RNA oxidation. Another important reason for this study is we want to compare RNA oxidation with other classic clinical indicators such as CRP or IL-6. For this purpose, we choose an intestinal pathogenic bacteria-V. parahaemolyticus to test the correlation of RNA oxidation and inflammation.

While several animal models have been developed for the study of oxidative stress, such as mice, rabbits and piglets, we select SD rats for animal model because of the large volume of urine they produced. Our results showed that the level of 8-oxoGsn other than 8-oxo-dGsn in urine was sharply increased from D0 to D5, peaking at D5 and gradually decreased until D18. The inflammatory indicators we tested including intestinal inflammation, WBCs and inflammatory cytokines were both increased from D0 to D5, peaking at D5 and gradually decreased until D18. What is more importantly is the trend of urinary 8-oxo-Gsn was consistent with WBCs and inflammation. It has very important clinical significance: $8-0 x 0-G s n$ is better than inflammatory cytokines in 
clinical, because it only needs urine samples. We also detected 8-oxo-Gsn and 8-oxodGsn in tissues, including small intestine, liver, spleen and colon. Consistent with the urine results, 8-oxo-Gsn was markedly increased in liver, spleen, small intestine and colon from D0 to D5 too, but however, D1 was higher than D5 in liver and colon, maybe there are some different mechanisms in these tissues. 8-oxo-dGsn had no changes in tissues except for the colon. These results suggested that $V$. parahaemolyticus can lead to a systemic RNA oxidation in our study.

What is the mechanism of the increase of RNA oxidation in urine and tissues? We think one possible explanation is that ROS produced by $V$. parahaemolyticus flooded the bloodstream and diffused into the tissues in forms such as superoxide $\left(\cdot \mathrm{O}_{2}^{-}\right)$, hydrogen peroxide $\left(\mathrm{H}_{2} \mathrm{O}_{2}\right)$ and hydroxyl radical $(\cdot \mathrm{OH})$. Another possible interpretation is that bacteria may have been carried by phygocytes to colonize the liver and spleen, thus inducing RNA oxidation; however, we did not detect any bacteria in liver or spleen. So another explanation maybe toxins, such as Shiga toxins and Shiga-like toxins (Stx1 or Stx2 with variants), especially Stx2, can reach many organs and induce oxidative stress ${ }^{24}$. We believe toxins produced by $V$. parahaemolyticus may be responsible for the RNA oxidation observed in our study, but is the direction of our future research. In a word, our results showed that 8-oxo-Gsn can be used as a more effective biomarker of clinical infection and prognosis compared with classic clinical indicators. 


\section{Conclusion}

This study found that SD rats were infected with $V$. parahaemolyticus can induce

232 the increasing of RNA oxidation and inflammation at the same time. Through the LC-

233 MS/MS-based system and IHC we proved the level of urinary and tissular 8-oxo-Gsn

234 rather than 8-oxo-dGsn was significantly elevated infection with V. parahaemolyticus.

235 Stimultaneously, white blood cells (WBCs), intestinal inflammation and inflammatory

236 factors were increased sharply. What is more clinical significance is that the trend of

237 urinary 8-oxo-Gsn was consistent with WBCs or inflammation. In a word, our results demonstrated that 8-oxo-Gsn can be used as a more effective biomarker of clinical infection and prognosis compared with classic clinical indicators. 


\section{Materials and Methods}

\section{Chemicals and Experimental Reagents}

High-performance liquid chromatography (HPLC)-grade solvents and ammonium acetate were purchased from Merk (Darmstadt, Germany) and Thermo Fisher

Scientific (St, Leon-Rot, Germany), respectively. 8-oxo-Gsn (>98\% purity), 8-oxo-

dGsn (>98\% purity) and isotope internal standard $\left[{ }^{15} \mathrm{~N}_{5}\right]$ 8-oxo-dGsn were purchased from Cambridge Isotope Laboratories (Andover, MA, USA). $\left[{ }^{13} \mathrm{C}_{1},{ }^{15} \mathrm{~N}_{2}\right]$ 8-oxo-Gsn was customized by Toronto Research Chemicals (Ontario, Canada). RNase A and DNase I were purchased from TaKaRa Biotechnology Co., Ltd. (Dalian, China). 15A3 and

N45.1 mAb were obtained from Abcam (Cambridge, UK). The H\&E Stain kit and DAB

Peroxidase (HRP) Substrate kit were purchased from Beijing Zhongshan Jinqiao

Biotechnology Co., Ltd. (Beijing, China). MILLIPLEX MAP Rat Cytokine/Chemokine

Kit was purchased from EMD Millipore Corporation (Billerica, MA, USA). The Luminex

200 system was obtained from Luminex Corporation (Austin, TX, USA). The Rat CRP

ELISA kit was come from Immunology Consultants Laboratory, Inc. (ICL, Portland, USA). Water used for the analysis was deionized at $18.2 \mathrm{M} \Omega$.

\section{Bacterial Strains and Culture Conditions}

V. parahaemolyticus (ATCC 17802) used in this study was come from American

270 Type Culture Collection (ATCC, Rockville, MD, USA), which was recovered from the

271 frozen conditions and streaked onto blood agar plates (Columbia agar supplemented

272 with $5 \%$ sheep blood, bioMérieux) to obtain some single colonies. A single colony was

273 inoculated in Tryptone Soya Broth (TSB) supplemented with 3\% $\mathrm{NaCl}$ liquid medium 
and shaken sharply at $35 \pm 2{ }^{\circ} \mathrm{C}$, and then $1 \%$ was transferred and cultured under the same conditions. The bacteria were harvested at the stationary growth phase for experimentation after being washed two times with sterile PBS.

277

\section{Animals and Treatments}

Twenty-four 3-week-old SPF male SD rats (80-90 g) were purchased from Beijing Vital River Laboratory Animal Technology Co., Ltd. These animals were housed in a temperature-controlled SPF chamber $\left(24 \pm 2{ }^{\circ} \mathrm{C}\right)$ with a $12-\mathrm{h}$ light/dark cycle for about one week to acclimate them to the environment. All animal operations were performed in a biosafety level 3 (BSL3) facility and were approved by the local ethics committee. These animals were divided into two groups: an infection group and a PBS control group. The infection group were challenged with $10^{10} \mathrm{CFU}$ bacteria per rat via gastric gavage, while the control group were orally administered sterile PBS. All animals were fasted for $16 \mathrm{~h}$ before treatments. Common clinical symptoms, including body weights, body temperatures, bacterial burden, WBCs, intestinal inflammation, inflammatory cytokines, urinary and tissular 8-oxoguanine were both analyzed. Urine samples were collected using the manual bladder palpation method and stored at $-80^{\circ} \mathrm{C}$. For tissue acquisition, three rats each were killed at D1, D5, D9 and D18 and immediately placed into $10 \%$ formalin-fixed liquid for the assessment of oxidative damage of DNA and RNA. To assess the concentration of WBCs in blood, samples were anticoagulated by $\mathrm{K}_{3}$ EDTA and subjected to a Sysmex XS-1000i hematology analysis (Sysmex Corp., Kobe, Japan) every four days. Serum samples were collected without anticoagulant and stored at $-80^{\circ} \mathrm{C}$ until analysis. 


\section{Bacterial Burden in Stool}

Bacterial burden of $V$. parahaemolyticus in stool were counted on chromogenic

298

299

300

301

302

303

304

305

306

307

308

309

310

311

medium (CHROMagar Microbiology, Paris, France). The bacteria appeared as mauve colonies in this selective solid medium. Quantitative analysis was applied to measure bacterial burden. In brief, stool samples were collected and weighed before grinding using a Pro200 rotor-stator homogeniser (PRO Scientific Inc., Oxford, CT USA). Stool samples were then centrifuged gently and diluted in PBS and plated onto plate. The mauve colonies were recorded as V. parahaemolyticus. All operations were performed in a BSL3 facility.

\section{Chromatographic and Mass Spectrometric Analyses}

All samples were separated using an Agilent 1290 Infinity ultra-HPLC (UHPLC) instrument (Agilent1290; California, USA). The chromatographic separation was performed on an Agilent $\mathrm{C} 18(3 \mu \mathrm{m}, 3.00 \times 100 \mathrm{~mm})$ column at $35^{\circ} \mathrm{C}$. The mobile phase consisted of mobile phase $\mathrm{A}$ ( $5 \mathrm{mM}$ ammonium acetate with $0.1 \%$ formic acid) and mobile phase $B$ (methanol with $0.1 \%$ formic acid). The flow rate was $0.4 \mathrm{~mL} / \mathrm{min}$. To reduce the loss of the sample solution, the sample room temperature was kept at $4{ }^{\circ} \mathrm{C}$. Early- and late-eluting components were discarded in order to ensure the data had no interference. The UHPLC conditions are summarized in supplementary Table 1. The UHPLC tandem mass spectrometry (UHPLC-MS/MS) instrument was equipped with an Agilent triple-quadrupole mass spectrometer with a JetStream ESI source and IFunnel (Agilent 6490; California, USA). The detection was performed in the positiveion detection mode, and multiple reaction mode (MRM) was monitored for the 
quantitative analysis. The optimum nitrogen value for the nebulizer was $30 \mathrm{psi}$, and the ESI needle voltage was $2000 \mathrm{~V}$. The temperature of the dry gas and sheath gas was set at 200 and $400^{\circ} \mathrm{C}$, respectively, while the flow rate was 16 and $12 \mathrm{~L} / \mathrm{min}$, respectively. The low- and high-pressure RF (radio frequency) was 50 and $120 \mathrm{~V}$, respectively. The optimized parameters are summarized in supplementary Tables 2 and 3.

\section{Detection DNA and RNA Oxidation Level in Urine Samples}

Urine samples frozen at $-80^{\circ} \mathrm{C}$ were thawed on ice and centrifuged at $7500 \mathrm{~g}$ for

$5 \mathrm{~min}$ at $4{ }^{\circ} \mathrm{C}$. To each $200 \mu \mathrm{L}$ aliquot of the supernatant, $200 \mu \mathrm{L}$ of working solution

327 (70\% methanol, 30\% water with $0.1 \%$ formic acid, $10 \mathrm{mM}$ ammonium acetate, $\mathrm{pH} 3.7)$ was added, followed by $10 \mu \mathrm{L}$ of 2 corresponding internal standards ( $240 \mathrm{pg} / \mu \mathrm{L})$. The mixtures were then incubated at $35 \pm 2{ }^{\circ} \mathrm{C}$ for $10 \mathrm{~min}$ and centrifuged at $12,000 \mathrm{~g}$ for 15 $\min$ at $4{ }^{\circ} \mathrm{C}$. Finally, $100 \mu \mathrm{L}$ of the supernatant was subjected to UHPLC-MS/MS.

331 Because of variations in the urinary volume and significant differences in the renal glomerular function, the concentration of analytes was adjusted by the creatinine level 25-27, which was determined using an automatic biochemical analyzer 7600 series (Hitachi High Technologies, Tokyo, Japan).

\section{Tissue Processing and Histopathologic Examinations} sections were stained with H\&E reagents according to the routine procedures. In brief, tissues were dehydrated in a graded series of alcohol washes, embedded in paraffin, 
sectioned into $4-\mu \mathrm{m}$ slices, followed by $\mathrm{H} \& \mathrm{E}$ stain for a microscopic examination. All sections were photographed using a 100 x light microscope (Nikon, Tokyo, Japan).

$342 \quad$ IHC

IHC was performed using labeled $4-\mu$ m-thick sections of formalin-fixed and paraffin-blocked sections. All sections were dewaxed using xylene and gradually dehydrated with gradient ethanol and washed with PBS. Antigen retrieval was performed by microwaveing at $95{ }^{\circ} \mathrm{C}$ for 40 min with buffer solution of citrate salts. For the detection of 8-oxo-dGsn in nuclear DNA, sections were treated with $5 \mathrm{mg} / \mathrm{mL}$ RNase A overnight at $37^{\circ} \mathrm{C}$ to eliminate cellular RNA. To detect 8-oxo-Gsn in cellular RNA, the sections were treated with DNase I overnight at $37^{\circ} \mathrm{C}$ to remove nuclear

DNA. After treatment with $3 \% \mathrm{H}_{2} \mathrm{O}_{2}$ for 20 min and blocking with $10 \%$ normal goat serum for $30 \mathrm{~min}$, the primary monoclonal antibodies $15 \mathrm{~A} 3$ to detect 8 -oxo-Gsn in cellular RNA and N45.1 to detect 8-oxo-dGsn in nuclear DNA were added to the tissue sections at $37^{\circ} \mathrm{C}$ for $2 \mathrm{~h}$. The sections were then incubated with a secondary antibody for 30 min at room temperature. All sections were treated with the HRP DAB Detection System (ZSGB BIO) for 20 min and visualized using a DAB kit (ZSGB-BIO).

\section{Inflammatory Cytokines detected by Luminex and ELISA}

The level of inflammatory cytokines was detected by the MILLIPLEX MAP Rat

Cytokine/Chemokine Kit and Luminex 200 system (Luminex Corporation, Austin, TX, USA). The procedures were according to the protocol in the kit. All reagents were to be balanced to room temperature before detection. First, $200 \mu \mathrm{L}$ assay buffer was added to each well of a 96-well plate and shaken on a plate shaker for $10 \mathrm{~min}$ at room 
temperature. Discarded assay buffer, added $25 \mu \mathrm{L}$ standards buffer, $25 \mu \mathrm{L}$ control buffer or $25 \mu \mathrm{L}$ assay buffer to the 96 -well plate, then $25 \mu \mathrm{L}$ serum matrix solution and $25 \mu \mathrm{L}$ serum, following $25 \mu \mathrm{L}$ beads. The plate was sealed and incubated with agitation for $2 \mathrm{~h}$ at room temperature. Each well was then washed twice using $200 \mu \mathrm{L}$ wash buffer. Detection antibodies $(25 \mu \mathrm{L})$ were added and incubated with agitation for $1 \mathrm{~h}$ at room temperature, after which $25 \mu \mathrm{L}$ Streptavidin-Phycoerythrin was added and incubated for 30 min at room temperature. Each well was washed twice using $200 \mu \mathrm{L}$ wash buffer, and then $125 \mu \mathrm{L}$ sheath fluid was added and shaken for $5 \mathrm{~min}$ to read on a Luminex 200 system.

The level of CRP was determined using a Rat CRP ELISA kit. The procedures were according to the protocol in the kit. All reagents were to be balanced to room temperature before testing. First, the serum samples were diluted 120000 times and then added to a 96 -well plate. The standard concentration were $0,6.25,12.5,25,50$, 100 and $200 \mathrm{ng} / \mathrm{mL}$. The plate was sealed and stored for $10 \mathrm{~min}$ at room temperature, followed by washing 5 times using $200 \mu \mathrm{L}$ wash buffer. Next, $100 \mu \mathrm{L}$ Enzyme-Antibody Conjugate was added, followed by incubation in dark for 10 min at room temperature and then washing 5 times using $200 \mu \mathrm{L}$ wash buffer with $100 \mu \mathrm{L}$ TMB substrate solution added. The plate was then incubated in dark at room temperature for 5 min before adding $100 \mu \mathrm{L}$ stop solution, at which point the $\mathrm{OD}_{450}$ value was determined, and the standard curve was drawn to calculate the CRP concentration.

\section{Statistical analysis}


mean \pm standard error of the mean (SEM). Differences between the PBS control and

385 the infection group were analyzed using an unpaired two-tailed Student's t-test or a 386 one-way analysis of variance. For all tests, a $P$ value of $<0.05$ was considered the 387 threshold for significance. All statistical analysis in this study were performed with the 388 GraphPad Prism 8.0 software program (GraphPad Software Inc, San Diego, CA, USA).

389 For correlation analysis of 8-oxo-Gsn with others, the receiver operator characteristic 390 (ROC) curve was accepted with the SPSS 20 software (IBM Corporation, Armonk, NY, 391 USA). 


\section{Abbreviations}

SPF: specific-pathogen-free; 8-oxo-Gsn: 8-oxo-7,8-dihydroguanosine; 8-oxo-dGsn: 8oxo-7,8-dihydro-2'-deoxyguanosine; IHC: immunohistochemistry; H\&E: hematoxylineosin; PBS: phosphate-buffered saline; V. parahaemolyticus: Vibrio parahaemolyticus; WBCs: white blood cells; ROS: reactive oxygen species; Cre: creatinine; SI: small intestine; ATCC: American Type Culture Collection; TSB: Tryptone Soya Broth; BSL3: biosafety level 3; MRM: multiple reaction mode; SEM: standard error of the mean; ROC: receiver operator characteristic.

\section{Authors' contributions}

Ya-ya Pian, Ji-hong Hu and Jian-ping Cai designed the study and wrote the manuscript. Ya-ya Pian and Jing-jing Nie performed the experiments and analyzed the data. Chenchen Wang, Qian Liu and Zhen Liu perfromed the MS work. Qiu-geng Ou-Yang, Guoqing fan, Li-qun Zhang and Lv-tao Zeng did the IHC job. Wei Zhang and Zhen-xiang Gao performed the experiments.

\section{Funding}

This work was supported by the CAMS Innovation Fund for Medical Sciences (No. 2018-I2M-1-002), National Key R\&D Program of China (2018YFC2000300), National Natural Science Foundation of China (No. 81571058), Beijing Hospital Doctor Foundation Project (bj-2018-027), Beijing Gold-Bridge Project (ZZ19059) and Beijing Dongcheng District Outstanding Talent Funding Project (2019DCT-M-11). 
429 Availability of data and materials

430 All data generated or analyzed during this study are included in this published article.

431

432 Ethics approval and consent to participate

433 The animal experiments were approved by the local ethics committee.

434

\section{Consent for publication}

$436 \quad$ Not applicable.

437

438 Competing interests

439 The authors declare that they have no competing interests.

440

\section{Acknowledgments}

442 We are grateful to the members of the Institute of Geriatrics of the Ministry of Health 443 for their advice and assistance. 


\section{References}

446 1. Song X-N, Zhang L-Q, Liu D-G, Lin J, Zheng J-D, Dai D-P, et al. Oxidative Damage to RNA and 447 Expression Patterns of MTH1 in the Hippocampi of Senescence-Accelerated SAMP8 Mice and 448 Alzheimer's Disease Patients. Neurochemical Research 2011; 36:1558-65.

449 2. Wang WX, Luo SB, Xia MM, Mao YH, Zhou XY, Jiang P, et al. Analysis of the oxidative damage of 450 DNA, RNA, and their metabolites induced by hyperglycemia and related nephropathy in Sprague 451 Dawley rats. Free Radic Res 2015; 49:1199-209.

3. Gan W, Liu XL, Yu T, Zou YG, Li TT, Wang S, et al. Urinary 8-oxo-7,8-dihydroguanosine as a Potential Biomarker of Aging. Front Aging Neurosci 2018; 10:34.

4. Ling PR, Smith RJ, Bistrian BR. Acute effects of hyperglycemia and hyperinsulinemia on hepatic oxidative stress and the systemic inflammatory response in rats. Crit Care Med 2007; 35:555-60.

5. Hardbower DM, de Sablet T, Chaturvedi R, Wilson KT. Chronic inflammation and oxidative stress: the smoking gun for Helicobacter pylori-induced gastric cancer? Gut Microbes 2013; 4:475-81. induces oxidative stress and programmed cell death in human gastric epithelial cells. Infect Immun $2007 ; 75: 4030-9$.

7. Patel B, Kumar P, Banerjee R, Basu M, Pal A, Samanta M, et al. Lactobacillus acidophilus attenuates Aeromonas hydrophila induced cytotoxicity in catla thymus macrophages by modulating oxidative stress and inflammation. Mol Immunol 2016; 75:69-83.

8. $\mathrm{Hu} \mathrm{JH}, \mathrm{Nie} \mathrm{JJ}, \mathrm{Gao} Z \mathrm{ZX}$, Weng QH, Wang ZH, Li CB, et al. Oxidative DNA and RNA damage and their prognostic values during Salmonella enteritidis-induced intestinal infection in rats. Free Radic Res 2018; 52:961-9. 
467 9. Su YC, Liu C. Vibrio parahaemolyticus: a concern of seafood safety. Food Microbiol 2007; 24:549-

468

469

58.

10. Zhang L, Orth K. Virulence determinants for Vibrio parahaemolyticus infection. Curr Opin Microbiol 2013; 16:70-7.

11. Jung SW. A foodborne outbreak of gastroenteritis caused by Vibrio parahaemolyticus associated with cross-contamination from squid in Korea. Epidemiol Health 2018; 40:e2018056.

12. Kawatsu K, Ishibashi M, Tsukamoto T. Development and evaluation of a rapid, simple, and sensitive immunochromatographic assay to detect thermostable direct hemolysin produced by Vibrio parahaemolyticus in enrichment cultures of stool specimens. J Clin Microbiol 2006; 44:1821-7.

13. Newton A, Kendall M, Vugia DJ, Henao OL, Mahon BE. Increasing rates of vibriosis in the United States, 1996-2010: review of surveillance data from 2 systems. Clin Infect Dis 2012; 54 Suppl 5:S3915.

14. Daniels NA ML, Bishop R, Altekruse S, Ray B, Hammond RM, Thompson S, Wilson S, Bean NH, Griffin PM, Slutsker L. Vibrio parahaemolyticus Infections in the United States, 1973-1998. J Infect Dis 2000; 181:1661-6.

15. William H Barker J, MD. and Eugene J. Gangarosa, MD. Food poisoning due to Vibrio parahaemolyticus. Annu Rev Med 1974; 25:75-81.

16. Jabs T. Reactive oxygen intermediates as mediators ofprogrammed cell death in plants and animals. Biochem Pharmacol 1999; 57:231-45.

17. Poulsen HE, Specht E, Broedbaek K, Henriksen T, Ellervik C, Mandrup-Poulsen T, et al. RNA modifications by oxidation: a novel disease mechanism? Free Radic Biol Med 2012; 52:1353-61.

18. Haghdoost S, Sjolander L, Czene S, Harms-Ringdahl M. The nucleotide pool is a significant target 

$58: 581-8$.

20. Gan W, Nie B, Shi F, Xu XM, Qian JC, Takagi Y, et al. Age-dependent increases in the oxidative damage of DNA, RNA, and their metabolites in normal and senescence-accelerated mice analyzed by LC-MS/MS: urinary 8-oxoguanosine as a novel biomarker of aging. Free Radic Biol Med 2012; 52:17007.

21. Nie B, Gan W, Shi F, Hu GX, Chen LG, Hayakawa H, et al. Age-dependent accumulation of 8oxoguanine in the DNA and RNA in various rat tissues. Oxid Med Cell Longev 2013; 2013:303181. assay for the determination of trelagliptin in rat plasma and its application to a pharmacokinetic study. J Chromatogr B Analyt Technol Biomed Life Sci 2016; 1033-1034:166-71. Gsn Could Be a Novel Evaluation Index for Patients with Chronic Kidney Disease. Oxid Med Cell Longev 2018; 2018:4237812.

24. !!! INVALID CITATION !!! [24,25].

25. Lee KF, Chung WY, Benzie IF. Urine 8-oxo-7,8-dihydro-2'-deoxyguanosine (8-oxodG), a specific marker of oxidative stress, using direct, isocratic LC-MS/MS: Method evaluation and application in study of biological variation in healthy adults. Clin Chim Acta 2010; 411:416-22. of urinary markers of nucleic acid oxidation. Scand J Clin Lab Invest 2014; 74:336-43. 
511 Sunyer J. Metabolism of hexachlorobenzene in humans: association between serum levels and urinary

512 metabolites in a highly exposed population. Environmental health perspectives. Environmental health

513 perspectives 1997; 105:78-83.

514

515 


\section{FIGURE LEGENDS}

517 Figure 1. The level of 8-oxo-Gsn was boosted in urine of SD rats after challenge with

518 V. parahaemolyticus. (A) and (B) indicated the concentration of 8-oxo-Gsn and 8-oxo-

519 dGsn in urine increased with the passage of time by UHPLC-MS/MS, respectively.

520 Creatinine (Cre) was used to normalize the oxidized guanosine level. All results are expressed as the mean \pm SEM. Statistical difference determined by the t-test. ${ }^{* *} p<0.01$, ${ }^{* * * *} p<0.0001$.

Figure 2. IHC determination for 8-oxo-dGsn in nuclear DNA and 8-oxo-Gsn in cellular RNA from tissues of rats. IHC stain for 8-oxo-Gsn in cellular RNA (A) and 8-oxo-dGsn in nuclear DNA (B) in small intestine (SI), spleen, colon and liver of SD rats at D0, D1, D5, respectively. All results are expressed as the mean \pm SEM. Significance determined using the t-test. ${ }^{*} p<0.05,{ }^{* *} p<0.01,{ }^{* * *} p<0.001,{ }^{* * *} p<0.0001$.

Figure 3. Inflammation heightened after infection with $V$. parahaemolyticus. (A) H\&E stain of the colon of SD rats challenged with $V$. parahaemolyticus at D0, D1, D5, D9 and D18. The red arrows indicate the infiltration of lymphocytes in colon. Images were taken at $\times 100$ magnification, except for the $\times 400$ magnification zoomed-in local view at D5. (B) WBCs of SD rats with and without V. parahaemolyticus infection at D0, D1, D5, D9, D13 and D18. All results are expressed as the mean \pm SEM. Significance determined using the t-test. ${ }^{*} p<0.05,{ }^{* *} p<0.01,{ }^{* * *} p<0.0001$. 
538 Figure 4. The concentration of inflammatory cytokines was increased after infection with V. parahaemolyticus. Luminex and ELISA were used to detect the concentration

540 of IL-6, IL-10, TNF- $\alpha$, IL-1 $\beta$ and IL-17A (A to E) and CRP (F), respectively. All results

541 are expressed as the mean \pm SEM. Significance determined using the t-test. ${ }^{*} p<0.05$, ${ }^{* *} p<0.01,{ }^{* * *} p<0.001,{ }^{* * * *} p<0.0001$.

544 Figure 5. The area under receiver operator characteristic (ROC) curve of 8-oxo-Gsn, WBCs and inflammatory cytokines including CRP, IL-6, IL-10, TNF- $\alpha$, IL-1 $\beta$ and IL$17 \mathrm{~A}$ for assessing the infection status. 


\section{Figure 1}

563
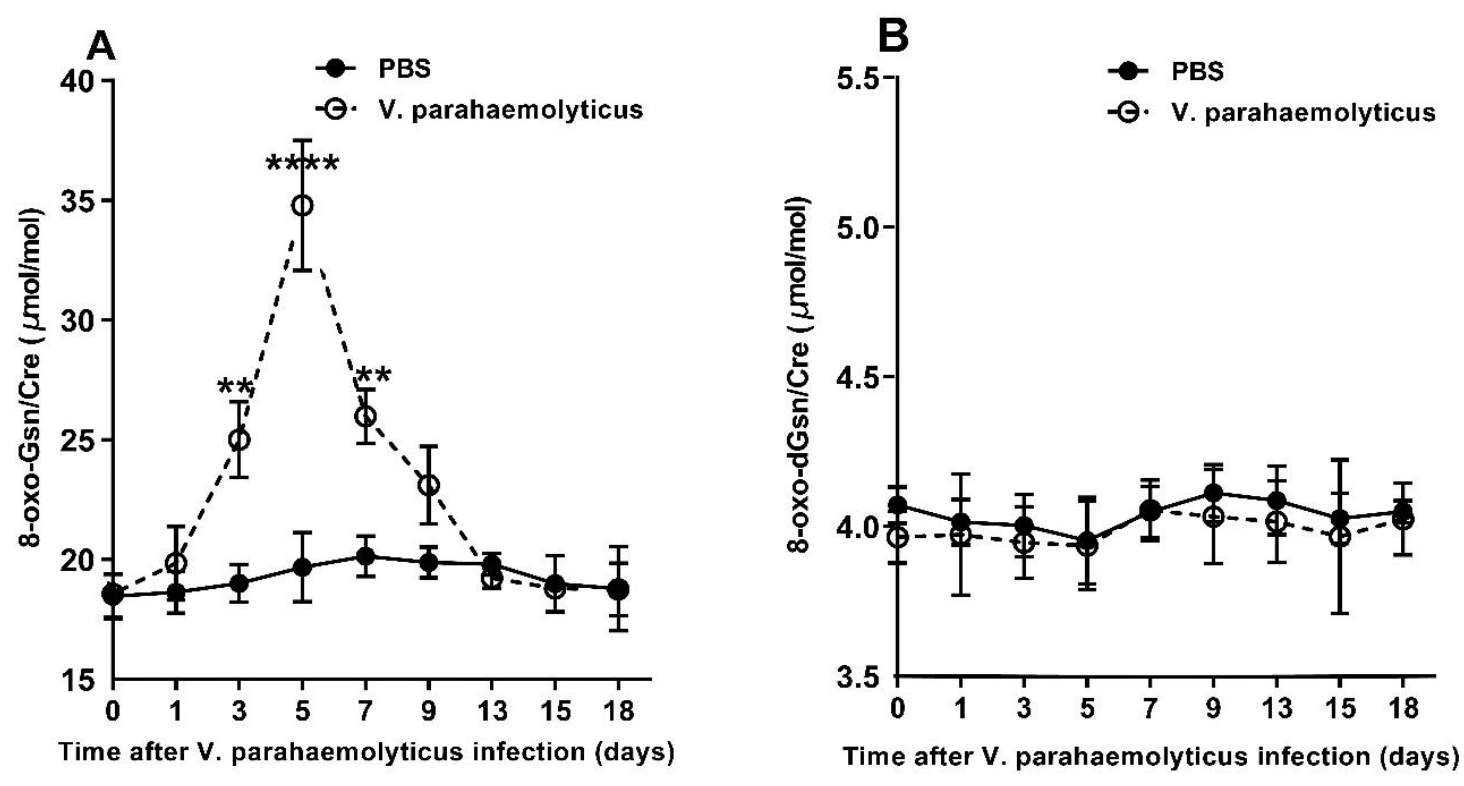

565

566

567

568

569

570

571

572

573

574

575 
A D1 D5
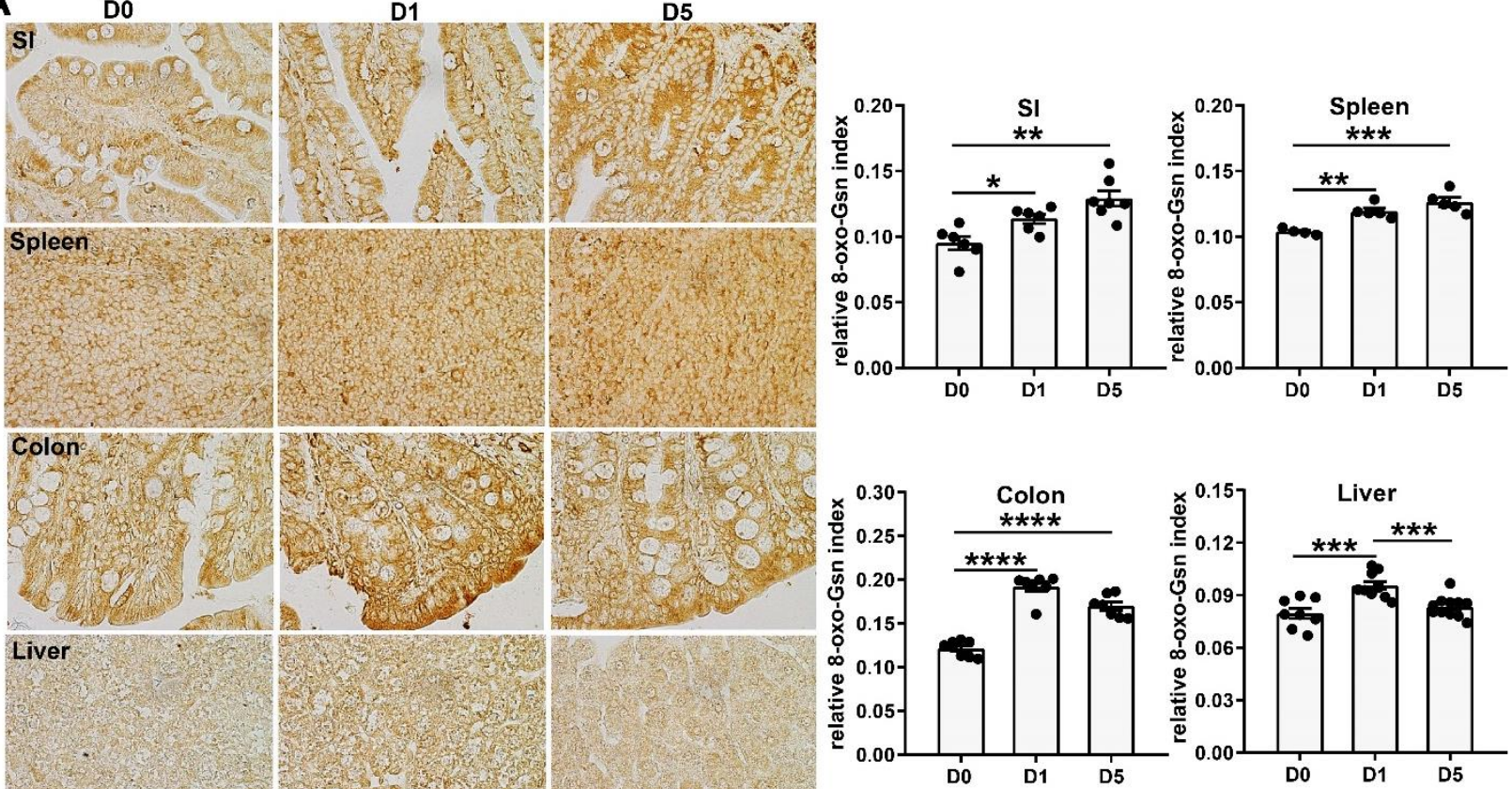

579

B
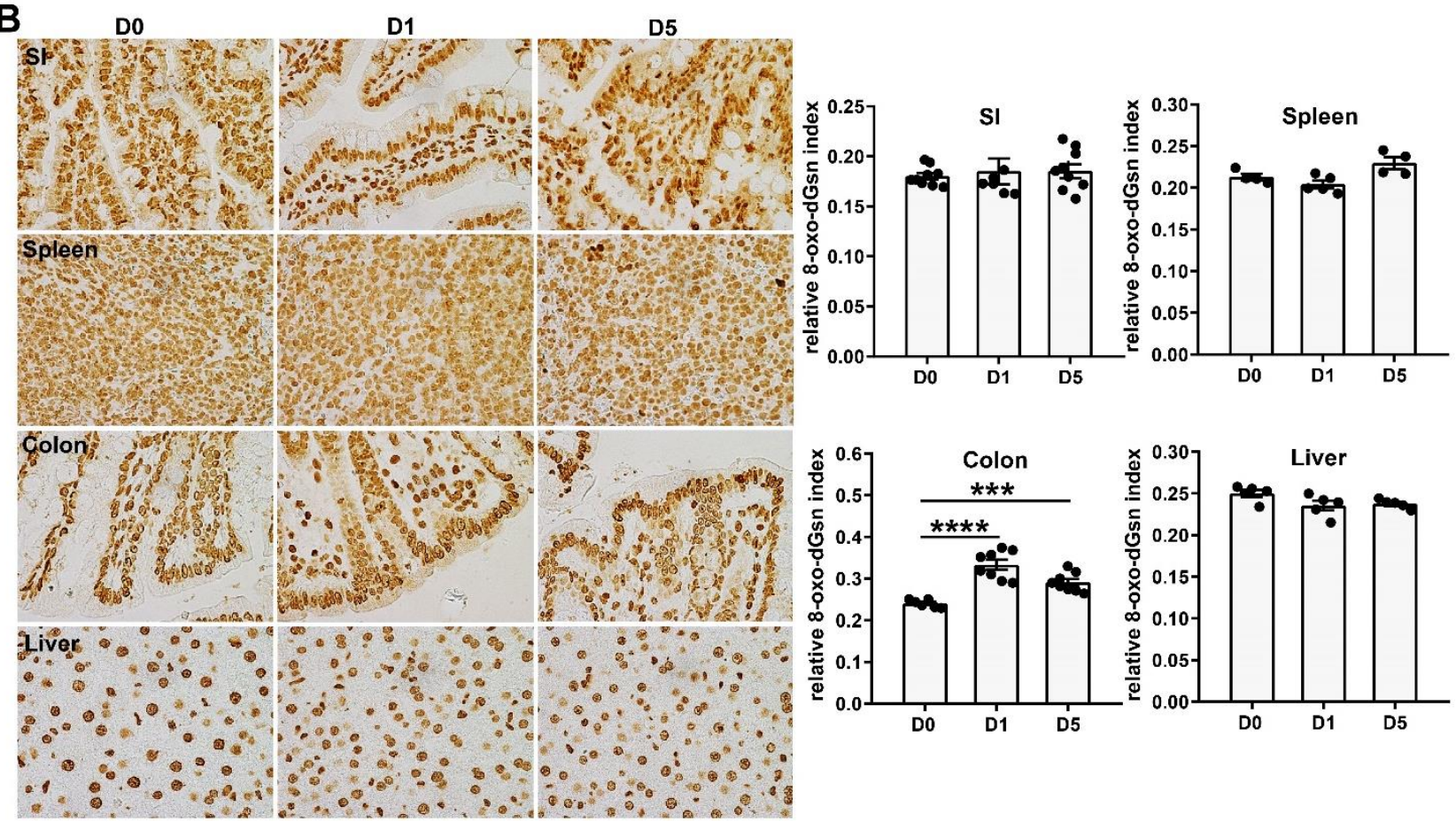
Figure 3

583
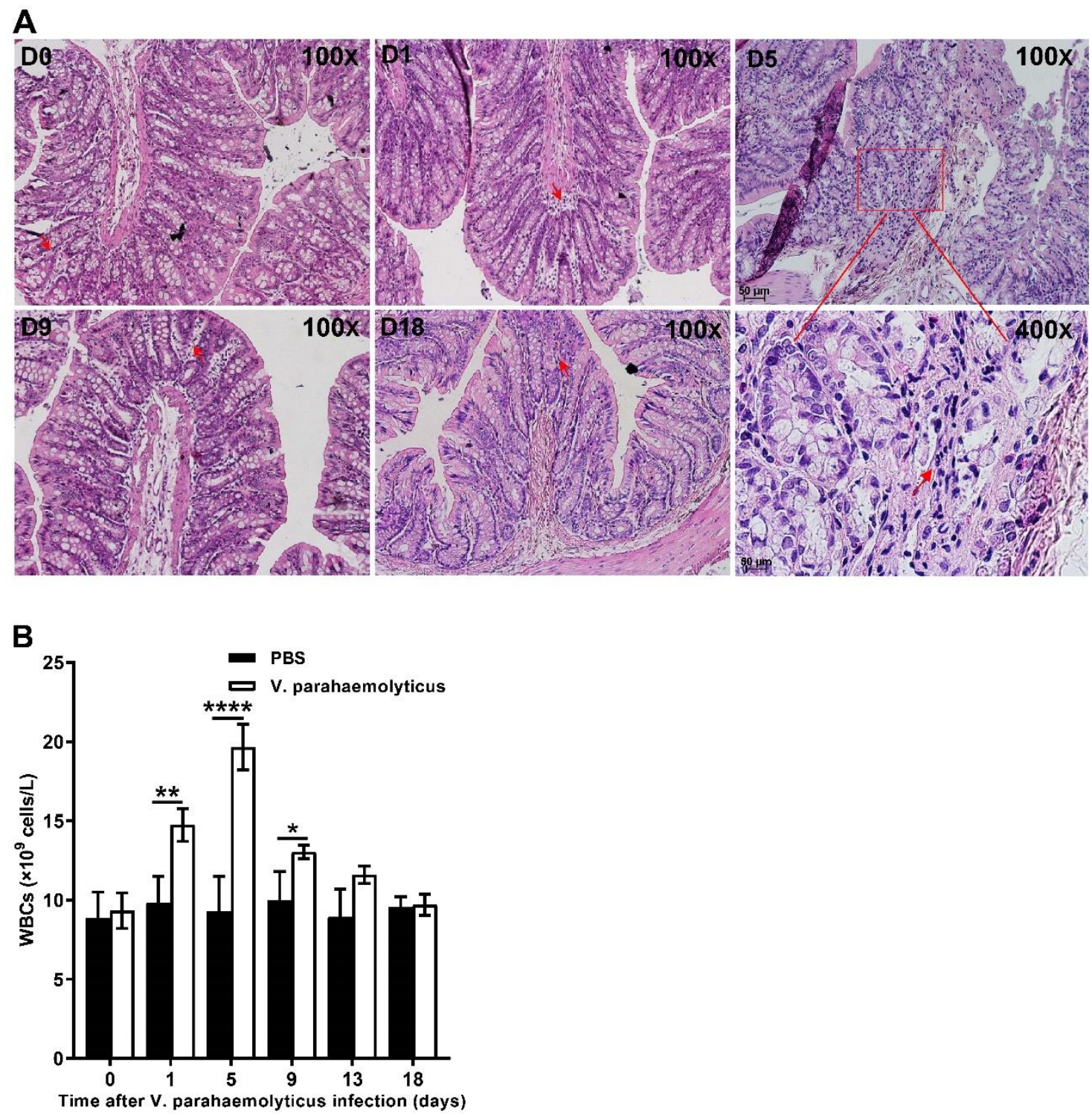

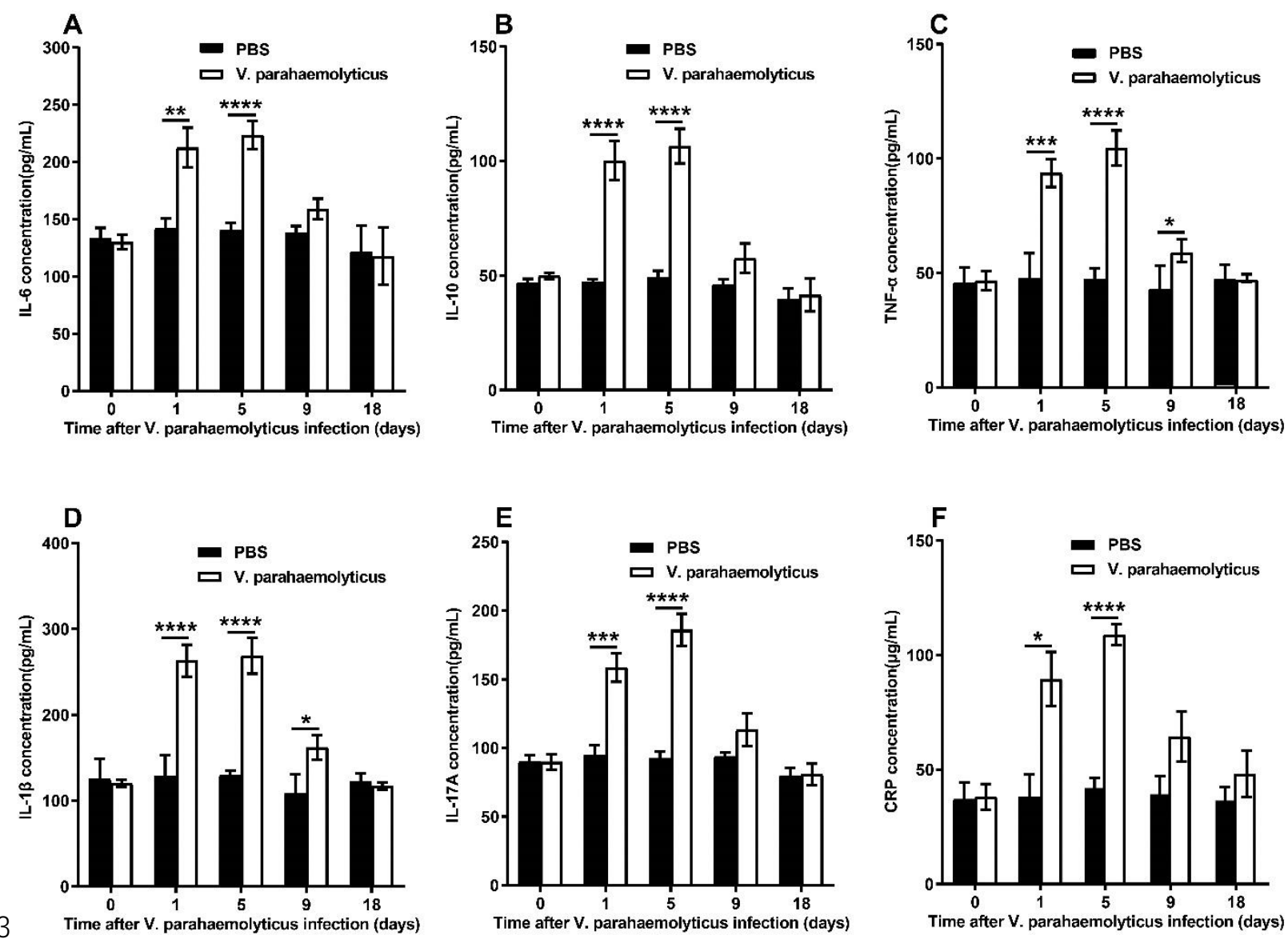
604
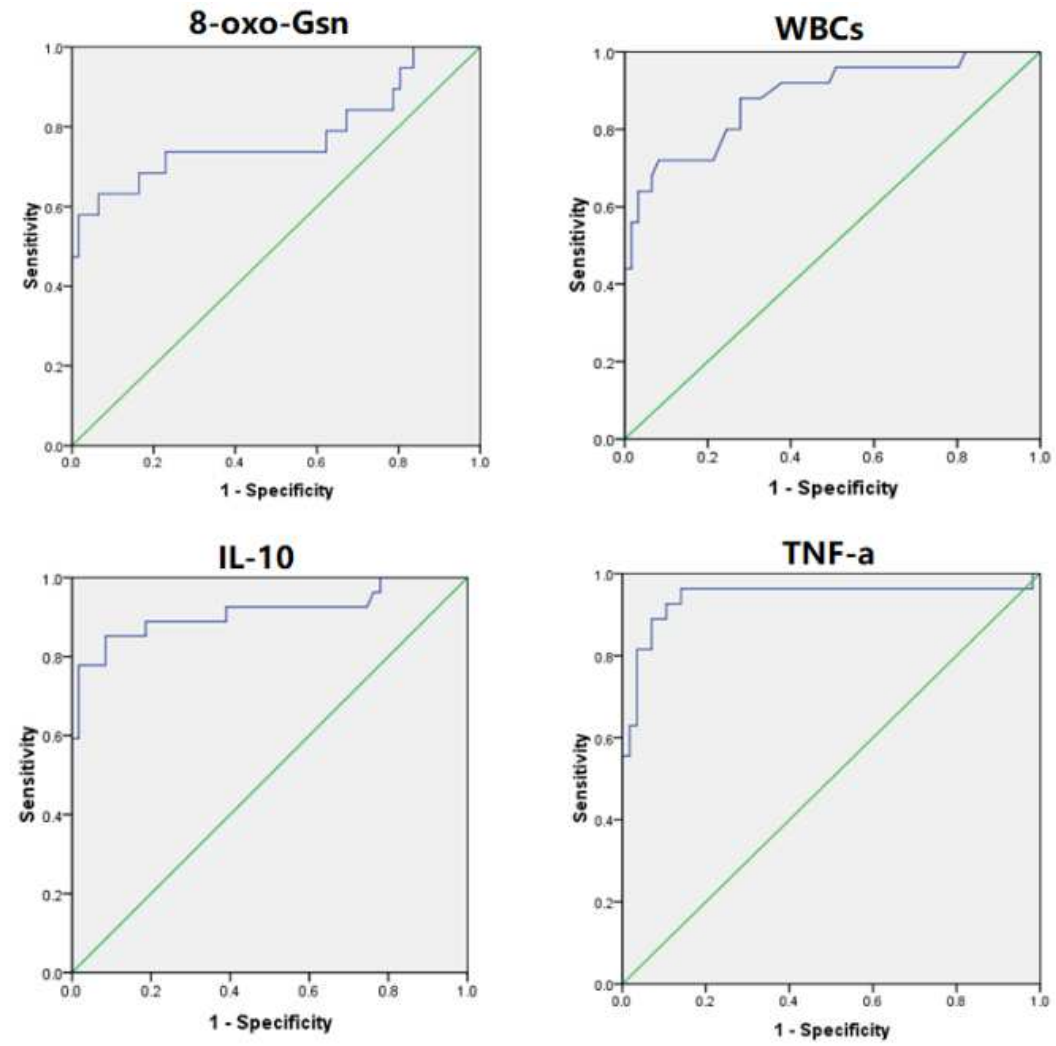

605
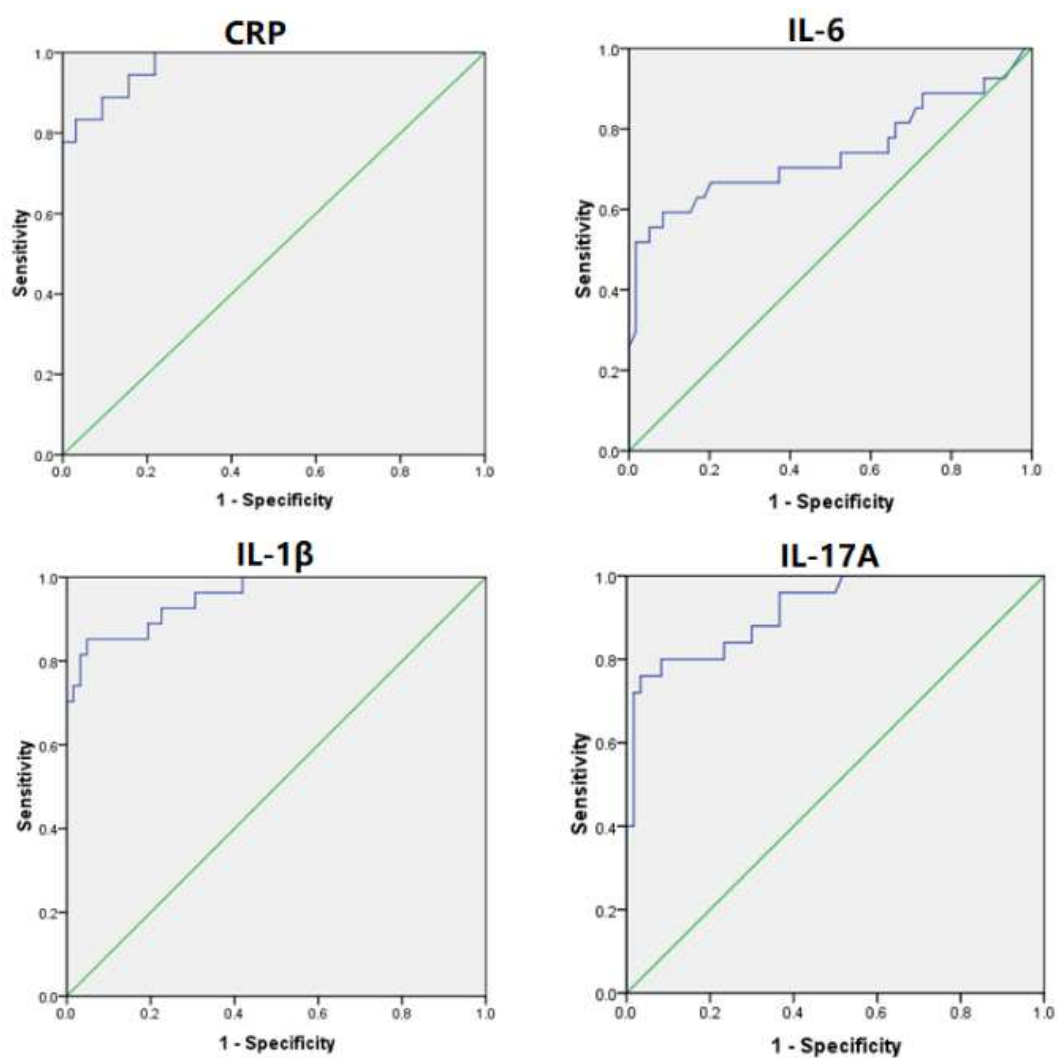


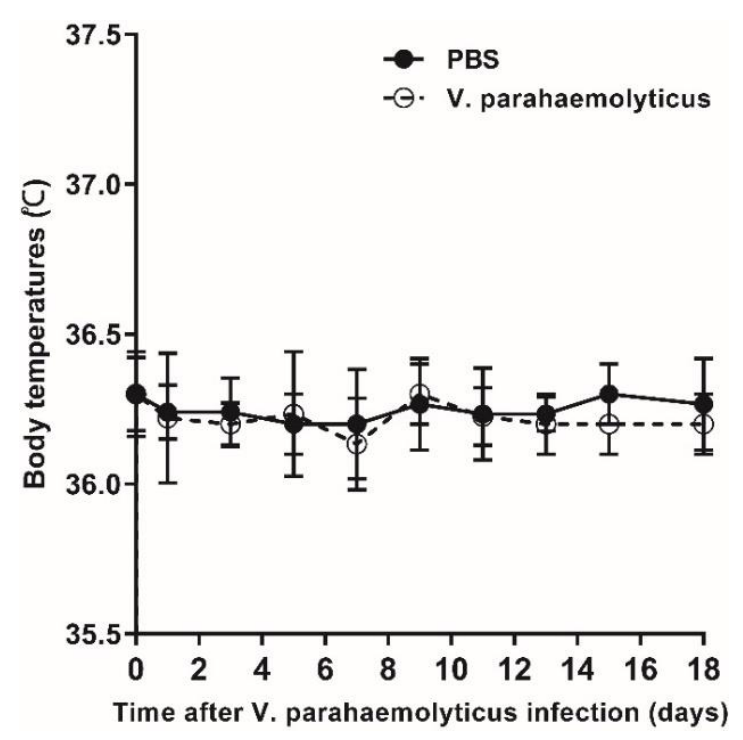

Supplementary Figure 1. Dynamic changes of body temperatures after SD rats were

612 challenged with V. parahaemolyticus. All rats were taken body temperatures every two 613 days.

614

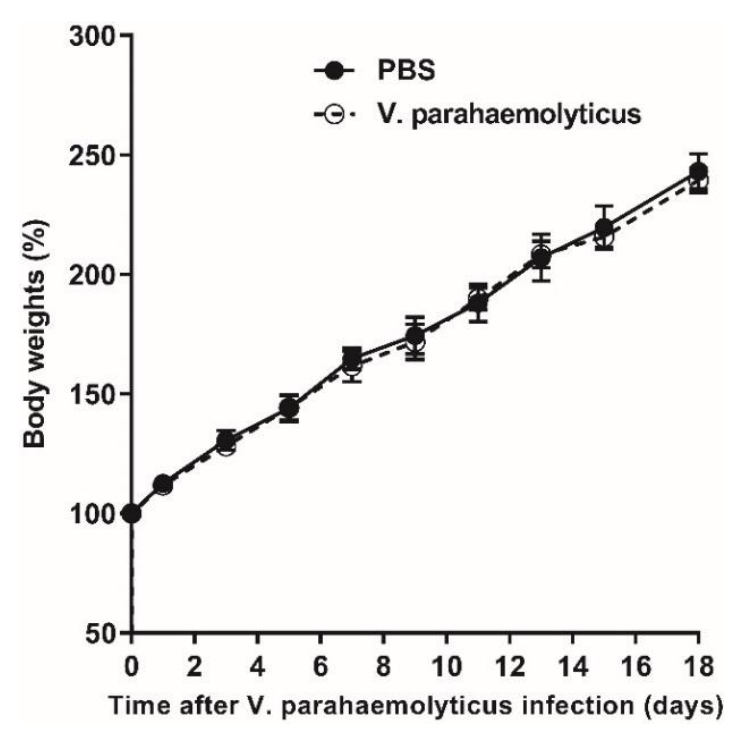

616 Supplementary Figure 2. Dynamic changes of body weights after SD rats were

617 challenged with V. parahaemolyticus. All rats were taken body weights every two days. 


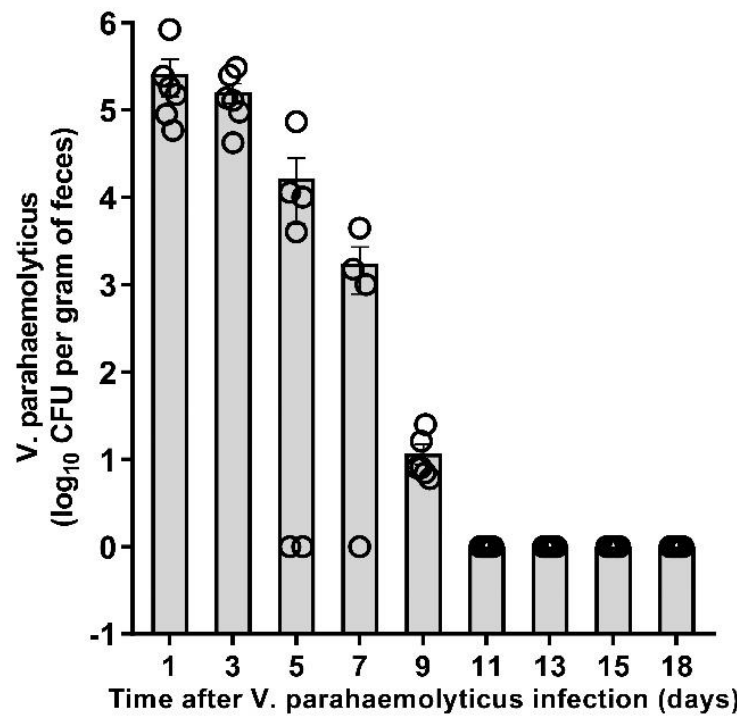

620 Supplementary Figure 3. Dynamic changes of bacterial burden per gram of stool

621 after SD rats were challenged with $V$. parahaemolyticus. The bacteria counts in the $V$. parahaemolyticus-infected group was determined every two days. 
Table 1. LC conditions for urine samples

\begin{tabular}{|c|c|c|c|c|c|c|c|}
\hline \multirow{2}{*}{$\begin{array}{l}\text { Sampl } \\
\text { e }\end{array}$} & \multirow{2}{*}{$\begin{array}{l}\text { Temperatur } \\
\mathrm{e}\end{array}$} & \multirow[t]{2}{*}{ Flow rate } & \multicolumn{5}{|c|}{ The percentage of mobile phase $A$ in relation to time } \\
\hline & & & $90 \%-70 \%$ & $70 \%-2 \%$ & $2 \%-2 \%$ & $2 \%-90 \%$ & $90 \%-90 \%$ \\
\hline urine & $35^{\circ} \mathrm{C}$ & $0.4 \mathrm{~mL} / \mathrm{min}$ & $0-3 \mathrm{~min}$ & 3-4 min & $4-5 \min$ & $5-5.01 \mathrm{~min}$ & $5.01-7 \mathrm{~min}$ \\
\hline
\end{tabular}

636

Table 2. Conditions for different compounds in urine samples

638

\begin{tabular}{|c|c|c|c|c|c|c|c|c|c|}
\hline sampl & Compound & MRM & Collision & MRM & Collision & \multicolumn{2}{|c|}{ Internal } & Collisio & Cell \\
\hline \multirow[t]{2}{*}{ e } & \multirow[t]{2}{*}{ s } & transitions & energy & transitions for & energy & \multicolumn{2}{|c|}{ standard } & $\mathrm{n}$ & accelerat \\
\hline & & for quantifier & & qualifier & & \multicolumn{2}{|c|}{ Mass pairs } & energy & or voltage \\
\hline \multirow[t]{4}{*}{ urine } & 8-oxo- & $m / z 284-168$ & $10 \mathrm{eV}$ & $\mathrm{m} / \mathrm{z} 284-140$ & $32 \mathrm{eV}$ & $m / z$ & $289-$ & $10 \mathrm{eV}$ & 3 \\
\hline & dGsn & & & & & \multicolumn{3}{|l|}{173} & \\
\hline & 8-oxo-Gsn & $m / z 300-168$ & $14 \mathrm{eV}$ & $\mathrm{m} / \mathrm{z} 300-140$ & $38 \mathrm{eV}$ & $m / z$ & $303-$ & $12 \mathrm{eV}$ & 3 \\
\hline & & & & & & \multicolumn{3}{|l|}{171} & \\
\hline
\end{tabular}

Table 3. MASS Conditions for urine samples

\begin{tabular}{|c|c|c|c|c|c|c|c|c|c|}
\hline Type of & Gas & Gas flow & Sheath & Sheath & Nebuliz & Capillar & Nozzle & High & Low \\
\hline \multirow[t]{3}{*}{ sample } & tempera & & gas & gas & er & $y$ & voltage & pressure & pressure \\
\hline & ture & & temperatu & flow & & & & $\mathrm{RF}$ & $\mathrm{RF}$ \\
\hline & & & re & & & & & & \\
\hline urine & $200^{\circ} \mathrm{C}$ & $16 \mathrm{~L} / \mathrm{min}$ & $400^{\circ} \mathrm{C}$ & $12 \mathrm{~L} / \mathrm{min}$ & 30 psi & $2000 \mathrm{~V}$ & 0 & $120 \mathrm{~V}$ & $50 \mathrm{~V}$ \\
\hline
\end{tabular}




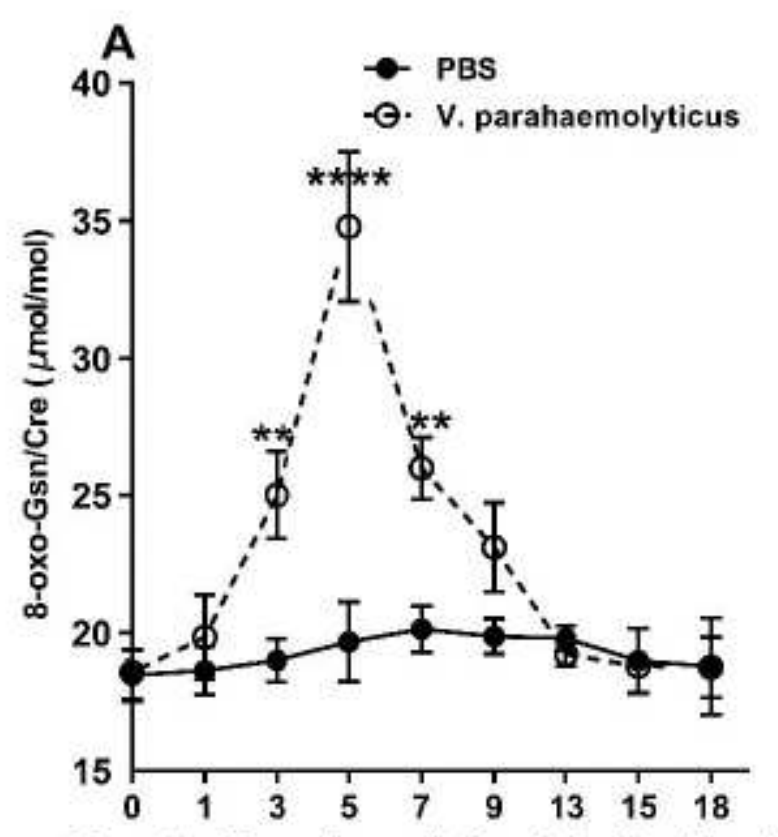

Time after $V$. parahaemolyticus infection (days)

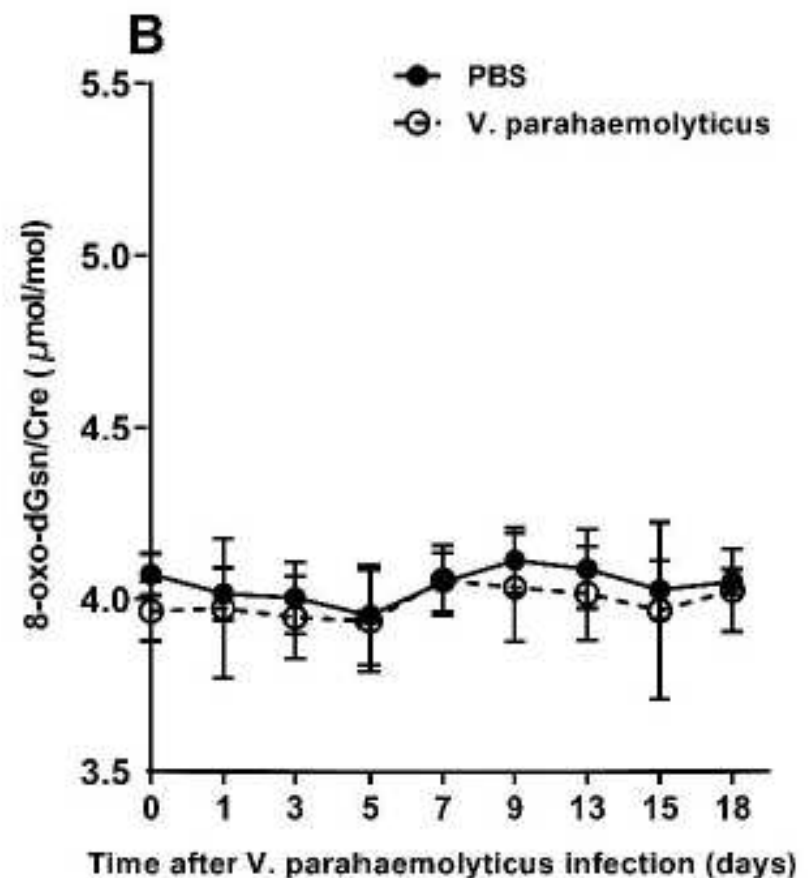

Time after $V$. parahaemolyticus infection (days)

\section{Figure 1}

The level of 8-oxo-Gsn was boosted in urine of SD rats after challenge with V. parahaemolyticus. (A) and (B) indicated the concentration of 8-oxo-Gsn and 8-oxo-dGsn in urine increased with the passage of time by UHPLC-MS/MS, respectively. Creatinine (Cre) was used to normalize the oxidized guanosine level. All results are expressed as the mean $\pm S E M$. Statistical difference determined by the t-test. ${ }^{\star \star} p<0.01,521$ $\star \star \star \star p<0.0001$. 
A


B
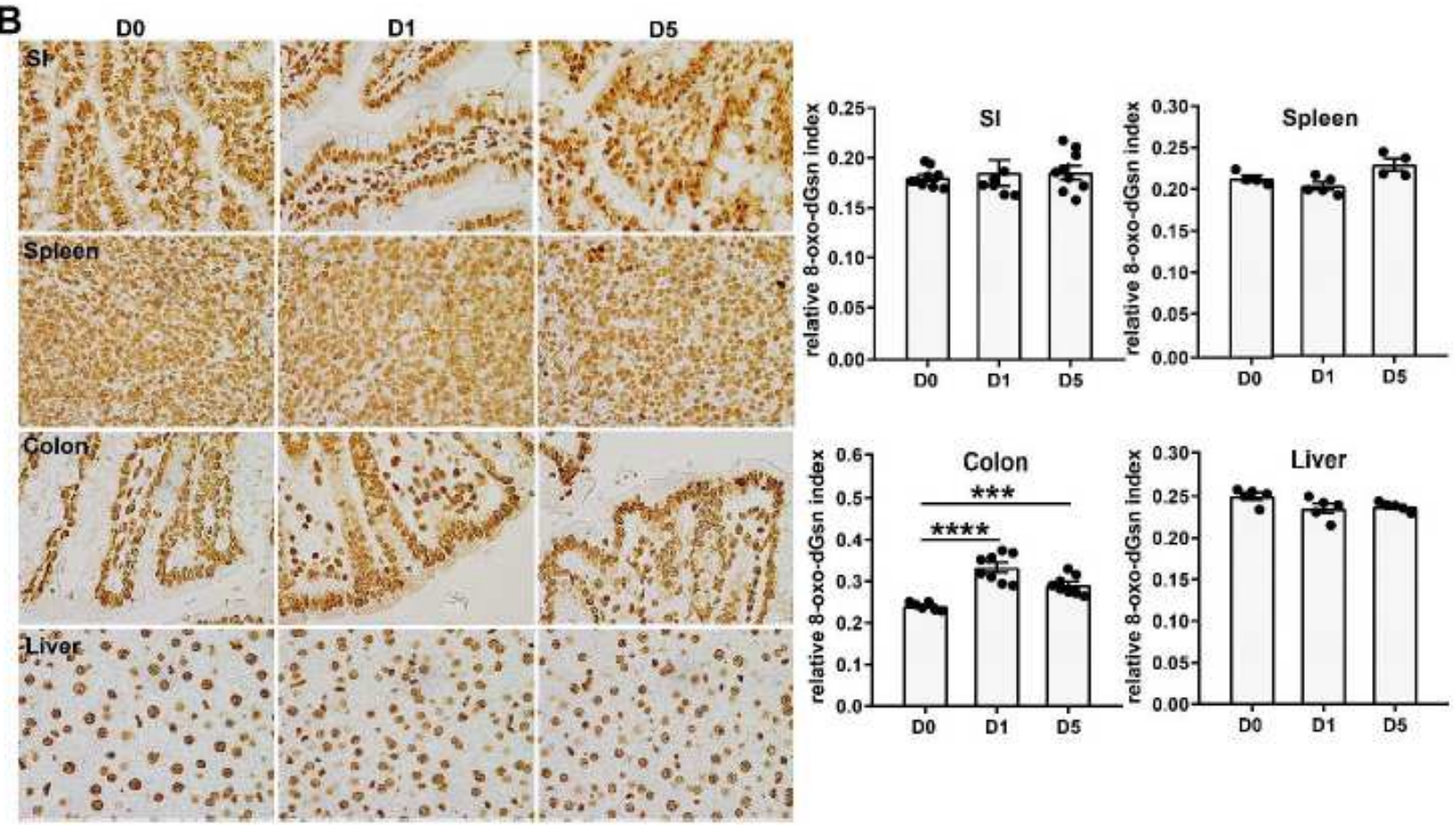

Figure 2

IHC determination for 8-oxo-dGsn in nuclear DNA and 8-oxo-Gsn in cellular RNA from tissues of rats. IHC stain for 8-oxo-Gsn in cellular RNA (A) and 8-oxo-dGsn in nuclear DNA (B) in small intestine (SI), spleen, colon and liver of SD rats at D0, D1, D5, respectively. All results are expressed as the mean \pm SEM. Significance determined using the t-test. ${ }^{\star} p<0.05,{ }^{\star \star} p<0.01,{ }^{\star \star \star} \mathrm{p}<0.001,{ }^{\star \star \star *} \mathrm{p}<0.0001$. 

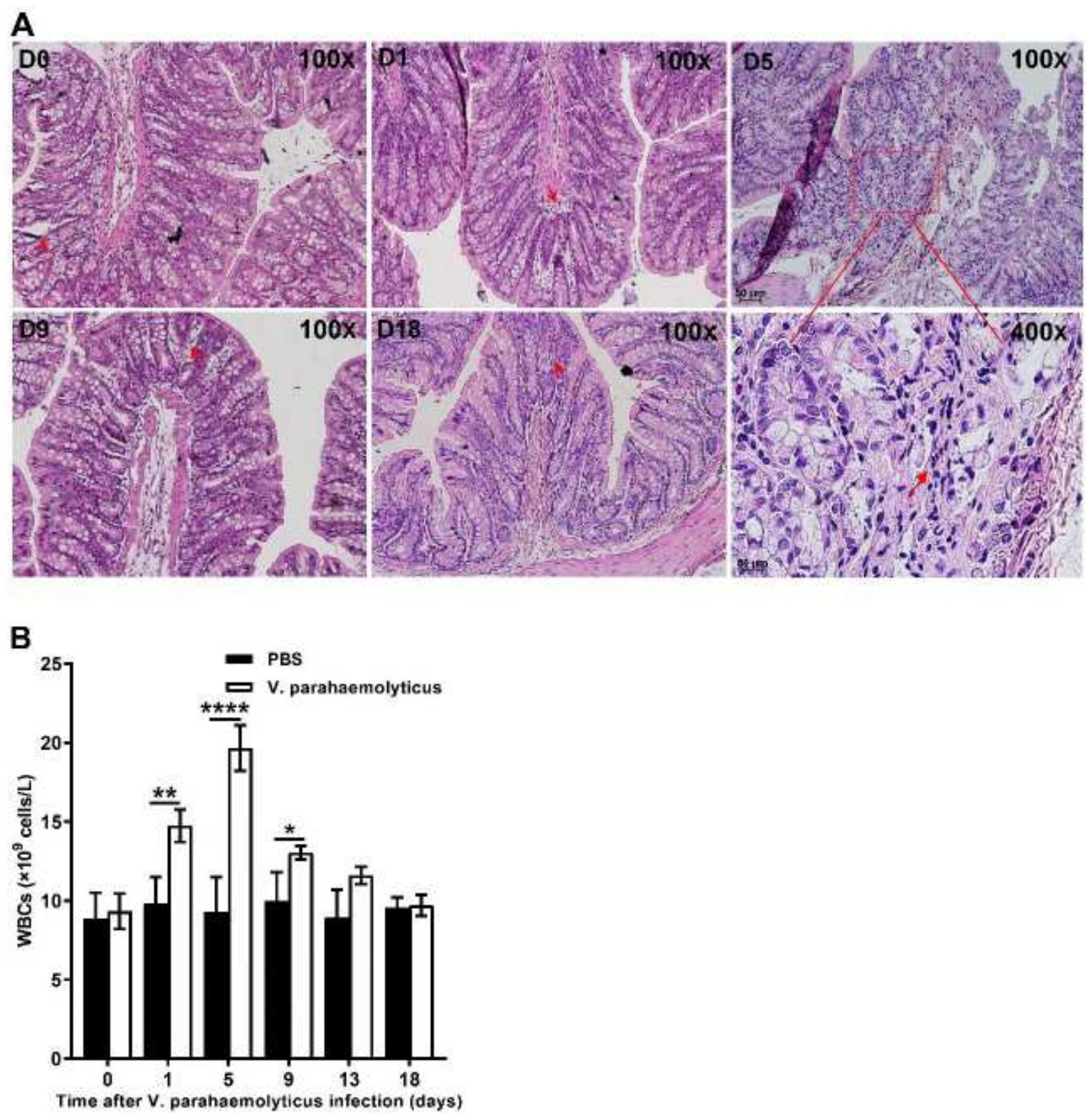

Figure 3

Inflammation heightened after infection with V. parahaemolyticus. (A) H\&E stain of the colon of SD rats challenged with V. parahaemolyticus at D0, D1, D5, D9 531 and D18. The red arrows indicate the infiltration of lymphocytes in colon. Images were taken at $\times 100$ magnification, except for the $\times 400$ magnification zoomed-in local view at D5. (B) WBCs of SD rats with and without V. parahaemolyticus infection at D0, D1, D5, D9, D13 and D18. All results are expressed as the mean \pm SEM. Significance determined using the t-test. ${ }^{*} p<0.05,{ }^{*} \mathrm{p}<0.01,{ }^{*} * \star * p<0.0001$. 

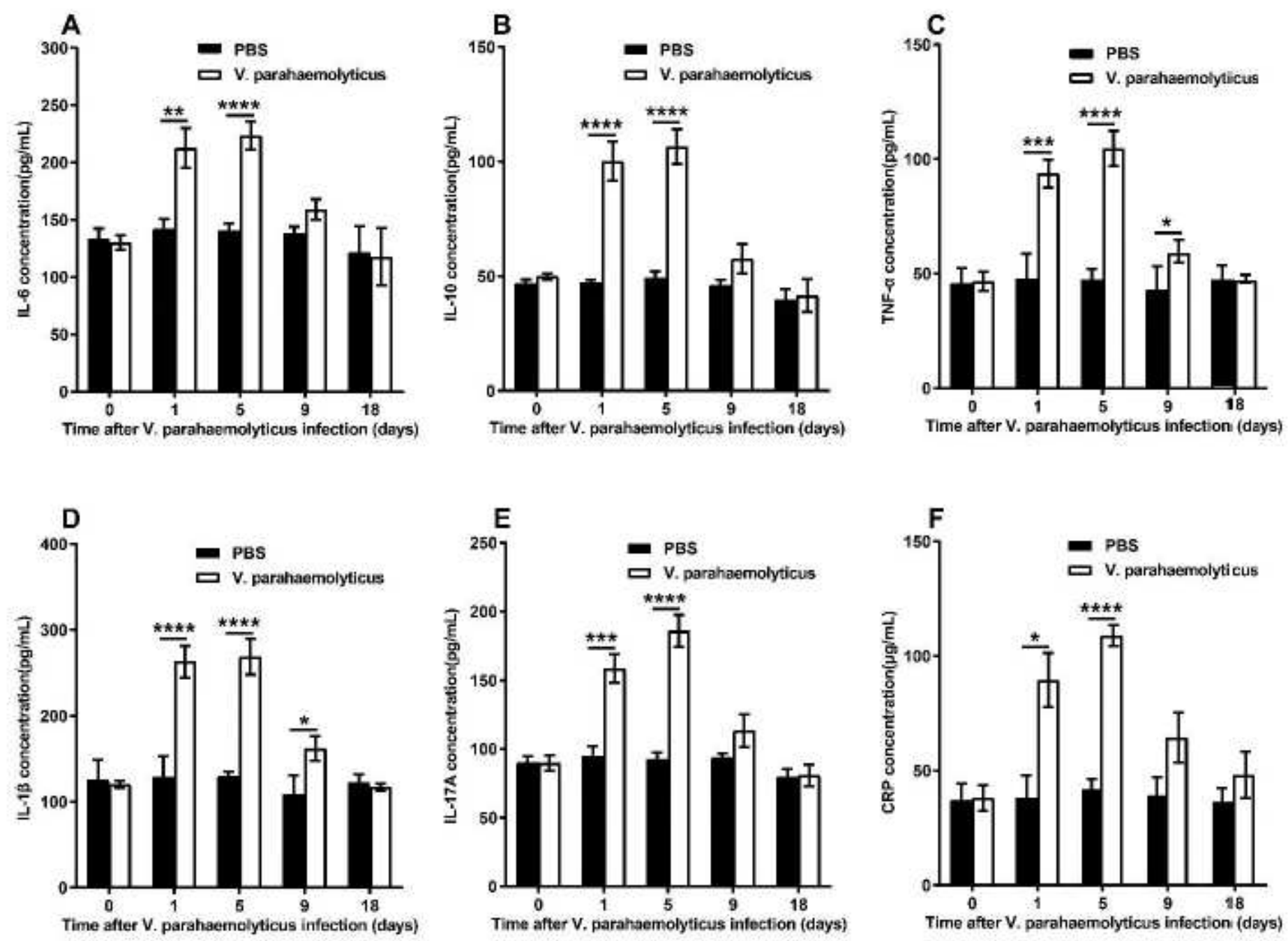

Figure 4

The concentration of inflammatory cytokines was increased after infection with V. parahaemolyticus. Luminex and ELISA were used to detect the concentration of IL-6, IL-10, TNF- $a$, IL-1 $\beta$ and IL-17A (A to E) and CRP $(F)$, respectively. All results are expressed as the mean \pm SEM. Significance determined using the t-test. ${ }^{*} \mathrm{p}<0.05,541{ }^{* \star} \mathrm{p}<0.01,{ }^{* \star *} \mathrm{p}<0.001,{ }^{* \star * *} \mathrm{p}<0.0001$. 

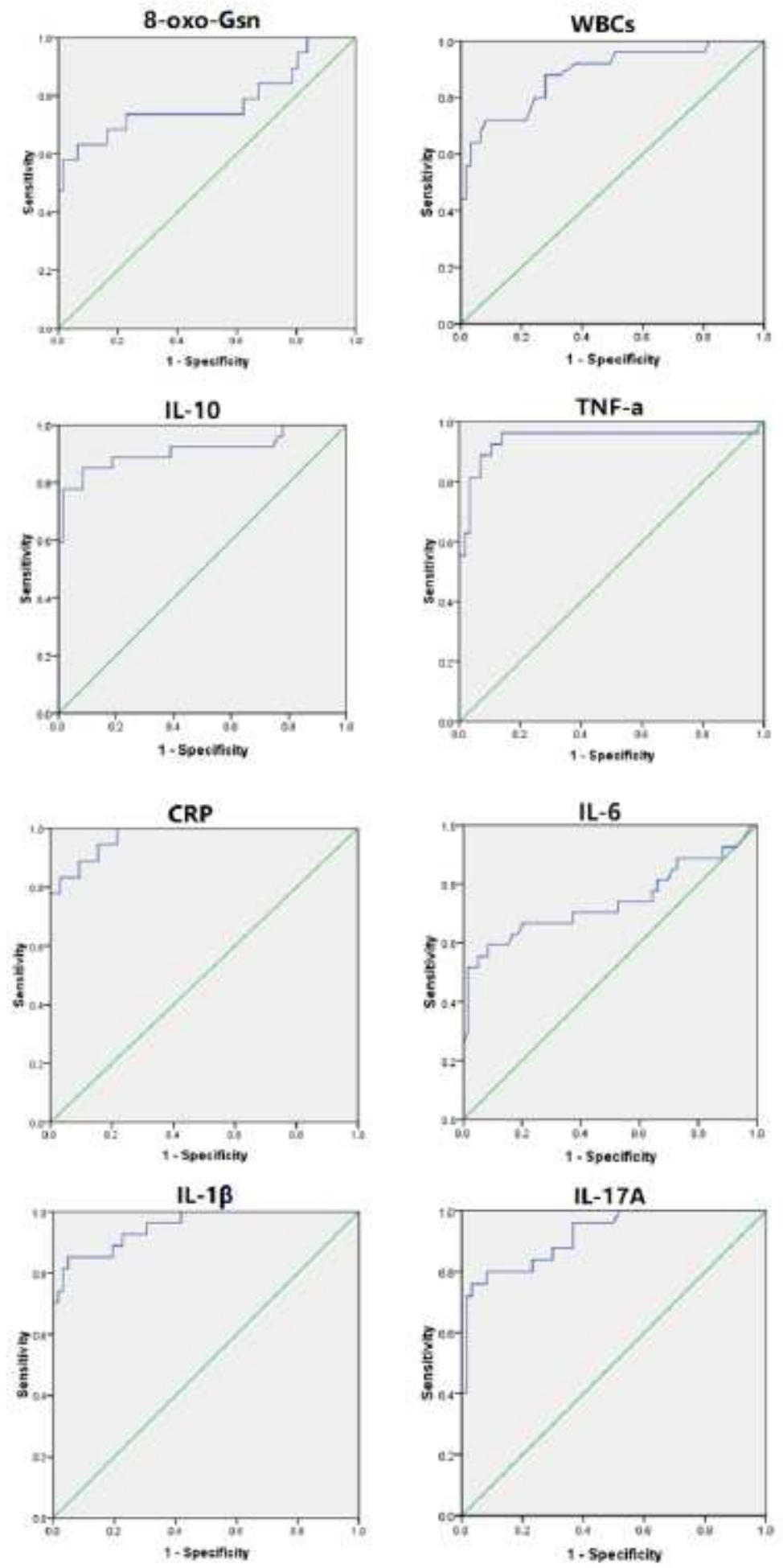

\section{Figure 5}

The area under receiver operator characteristic (ROC) curve of 8-oxo-Gsn, WBCs and inflammatory cytokines including CRP, IL-6, IL-10, TNF-a, IL-1 $\beta$ and IL-17A for assessing the infection status.

\section{Supplementary Files}


This is a list of supplementary files associated with this preprint. Click to download.

- FigureS3.jpg

- FigureS1.jpg

- FigureS2.jpg 